\title{
Ferromagnetic Levan Composite: An Affinity Matrix to Purify Lectin
}

\author{
Renata Angeli, ${ }^{1,2}$ Nathalia V. N. da Paz, ${ }^{1}$ Jackeline C. Maciel, ${ }^{1,3}$ Flávia F. B. Araújo, ${ }^{1}$ \\ Patrícia M. G. Paiva, ${ }^{1}$ Glícia M. T. Calazans, ${ }^{4}$ Ana Paula Valente, ${ }^{2}$ Fábio C. L. Almeida, ${ }^{2}$ \\ Luana C. B. B. Coelho, ${ }^{1}$ Luiz B. Carvalho Jr., ${ }^{1,2}$ Maria da Paz C. Silva, ${ }^{1,2}$ \\ and Maria Tereza dos Santos Correia ${ }^{1}$
}

${ }^{1}$ Laboratório de Glicoproteínas, Departamento de Bioquímica, Universidade Federal de Pernambuco (UFPE), 50670-901 Recife, PE, Brazil

${ }^{2}$ Centro Nacional de Ressonância Magnética Nuclear de Macromoléculas, Instituto de Bioquímica Médica, Universidade Federal do Rio de Janeiro, 21941-590 Rio de Janeiro, RJ, Brazil

${ }^{3}$ Laboratório de Imunopatologia Keizo Asami (LIKA), UFPE, 50670-901 Recife, PE, Brazil

${ }^{4}$ Departamento de Antibióticos, Universidade Federal de Pernambuco (UFPE), 50670-901 Recife, PE, Brazil

Correspondence should be addressed to Maria Tereza dos Santos Correia, mtscorreia@gmail.com

Received 15 February 2009; Accepted 6 May 2009

Recommended by Elvira Gonzalez De Mejia

A simple and inexpensive procedure used magnetite and levan to synthesize a composite recovered by a magnetic field. Lectins from Canavalia ensiformis (Con A) and Cratylia mollis (Cramoll 1 and Cramoll 1,4) did bind specifically to composite. The magnetic property of derivative favored washing out contaminating proteins and recovery of pure lectins with glucose elution. Cramoll 1 was purified by this affinity binding procedure in two steps instead of a previous three-step protocol with ammonium sulfate fractionation, affinity chromatography on Sephadex G-75, and ion exchange chromatography through a CM-cellulose column.

Copyright (C) 2009 Renata Angeli et al. This is an open access article distributed under the Creative Commons Attribution License, which permits unrestricted use, distribution, and reproduction in any medium, provided the original work is properly cited.

\section{Introduction}

Techniques involving solid supports play crucial roles in the development of genomics, proteomics, and in molecular biology. However, solid-phase tools have been employed to a much lesser extent in glycobiology and glycomics [1]. There are a number of "classical" methods for immobilization of mono- and oligosaccharides to commercially available matrices and supports. These methods have, for example, been used for the preparation of affinity columns with specific ligands [1]. Increased attention has been given to the development and application of magnetic separation techniques, which employ small magnetic particles. Antibodies, DNA/RNA/oligonucleotide/aptamer binding proteins, albumin, hemoglobin, and enzymes have been purified by magnetic techniques [2].

In our laboratory $\mathrm{Fe}_{3} \mathrm{O}_{4}$ magnetite particles prepared by coprecipitating $\mathrm{Fe}_{2}{ }^{+}$and $\mathrm{Fe}_{3}{ }^{+}$with either Dacron or a network of polysiloxane-polyvinyl alcohol have been synthesized [3-6]. Here, magnetic particles containing levan, a homopolysaccharide of fructose residues in 2, 6-glycosidic linkage, are proposed to purify lectins. The latter glycoproteins and/or oligomeric proteins are found in a diverse assortment of organisms and have the extraordinary property of binding specifically, reversibly, and noncovalently to carbohydrates [7]. Lectin-carbohydrate interactions are extensively studied in different scientific disciplines, from basic to applied natural and clinical sciences. Such inter- and multidisciplinarity corroborates the importance to develop new methodologies for the study of lectin-saccharide interactions and the potential applications in clinical diagnostics [8].

In the present work a composite of the carbohydrate levan and magnetite was easily synthesized and recovered by a magnetic field. Lectins complexed specifically to the composite were separated from other contaminant proteins 
by washing with a high ionic strength solution and obtained from composite with specific monosaccharide. Finally, these proteins were collected from supernatant and the composite reused. The washing procedures were facilitated by the magnetic field and all process can be automated. The seed lectins from Cratylia mollis (Camaratu bean), Cramoll $[9,10]$ and Canavalia ensiformis (Con A) were used as models. Con A and potato lectin from Solanum tuberosum have already been purified by magnetic techniques using dextran [11] and chitosan [12] as ligands, respectively.

The aim of this work was to evaluate the use of Zimomonas mobilis levans insolubilized and ferromagnetized (FMZAG-12L), to purify fructose/specific lectins using lectin preparations of $C$. mollis seeds.

\section{Material and Methods}

2.1. General Methods. Cramoll 1,4 and Cramoll 1 were obtained through a previously established protocol [10] from a C. mollis seed extract $(10 \%, \mathrm{w} / \mathrm{v})$ that was ammonium sulfate fractionated; fraction (F) 40 to $60 \%$ saturated (F40-60) was affinity chromatographed in Sephadex G-75 (Cramoll 1,4) followed by ion exchange chromatography in CM-cellulose (Cramoll 1 and Cramoll 4). Cramoll 3 was also obtained from the above mentioned seed extract through a previously described protocol [10]; the 0 to $40 \%$ ammonium sulfate fraction (F0-40) was molecular exclusion chromatographed in Sephadex G-100. Con A was purchased from SIGMA (USA). Levan (L) was produced by Zimomonas mobilis strain ZAG-12 (Departamento de Antibióticos, Universidade Federal de Pernambuco, Brazil) and abbreviated from now on as ZAG-12L. All other chemical reagents used were of analytical grade.

2.2. Ferromagnetic Levan Particles Synthesis. The composite synthesis was based on the technique described by Carneiro Leão et al. [3], as briefly described. A solution containing $\mathrm{Fe}^{3+}$ and $\mathrm{Fe}^{2+}$ ions in a molar ratio of $1.1 \mathrm{M}: 0.6 \mathrm{M}$ was prepared from $\mathrm{FeCl}_{3} \cdot 6 \mathrm{H}_{2} \mathrm{O}$ and $\mathrm{FeCl}_{2} \cdot 4 \mathrm{H}_{2} \mathrm{O}$ in distilled water; $50 \mathrm{~mL}$ of $2 \%$ ZAG-12L in distilled water was then added and the $\mathrm{pH}$ was raised to 11.0 by adding drop wise $1 \mathrm{M} \mathrm{NH}_{4} \mathrm{OH}$. Mixture was then heated up to $85 \pm 3^{\circ} \mathrm{C}$ and incubated for 30 minutes with vigorous stirring. The ferromagnetic levan obtained (FMZAG-12L) was centrifuged 5 times to remove solid material. The product was dried for 24 hours at $50^{\circ} \mathrm{C}$, ground and kept at room temperature. Magnetic particles were prepared in the presence of polysaccharide levan. Aqueous suspensions of magnetic particles were prepared by coprecipitation of $\mathrm{Fe}$ (III) and Fe (II) in the presence of $\mathrm{NH}_{4} \mathrm{OH}$ and polymer.

2.3. Protein Determination. The protein content was carried out by Lowry et al. [13] using bovine serum albumin as standard, at a range of $0-500 \mu \mathrm{g} / \mathrm{mL}$ and absorbance reading at $720 \mathrm{~nm}$. Absorbance at $280 \mathrm{~nm}$ was used to determine the relative concentration of eluted fractions.
2.4. Hemagglutinating Activity and Lectin Hemagglutinating Inhibition. Lectin sample solutions $(50 \mu \mathrm{L})$ were serially 2 fold diluted in $0.15 \mathrm{M} \mathrm{NaCl}$, in microtiter U-plates and incubated with of a $2.5 \%(\mathrm{v} / \mathrm{v})$ suspension of glutaraldehyde treated erythrocytes from New Zealand white rabbit $(50 \mu \mathrm{L})$. The titer, defined as the lowest sample dilution which showed hemagglutination, was established after 45 minutes incubation according to Correia and Coelho [10]. Hemagglutinating activity (HA) corresponded to the reciprocal titer. The HA inhibition (HAI) was assayed by 2 -fold serial dilution of lectin sample solutions $(50 \mu \mathrm{L})$ in $50 \mu \mathrm{L}$ of $200 \mathrm{mM}$ levan or fructose solutions, followed by 15 minutes incubation and addition of erythrocyte suspension. The HAI titer was obtained by the HA establishment after 45 minutes.

2.5. ZAG-12L by Nuclear Magnetic Resonance Spectroscopy (NMR). ${ }^{1} \mathrm{H}$ unidimensional spectra were recorded in a BRUKER DRX 400MHz (Bruker, Germany) with a triple resonance $5-\mathrm{mm}$ probe. About $1 \mathrm{mg}$ of ZAG-12L was dissolved in $0.5 \mathrm{~mL}$ of $99.8 \% \mathrm{D}_{2} \mathrm{O}$. All spectra were recorded at $60^{\circ} \mathrm{C}$.

2.6. Binding Evaluation of Con A, Cramoll 1, 4, Cramoll 3 and F40-60 with FMZAG-12L. The lectins $(1 \mathrm{~mL})$ Con A, Cramoll 1, 4, Cramoll 3, and F40-60 were each incubated with FMZAG-12L particles ( $1 \mathrm{~mL}$ containing $10 \mathrm{mg}$ ) for 2 hours at $4^{\circ} \mathrm{C}$, under constant agitation. Afterwards, the magnetic particles were recovered by a magnetic field $(6000 \mathrm{Oe})$ and supernatant was collected. The remaining unspecific bound proteins were eluted with $0.15 \mathrm{M} \mathrm{NaCl}(1 \mathrm{~mL})$ by recovering the magnetic particles under the magnetic field and collecting the supernatant. Finally, adsorbed lectin was eluted with either 0.3 M D-glucose (Con A and Cramoll $1,4)$ or D-galactose (Cramoll 3 incubation) in $0.15 \mathrm{M} \mathrm{NaCl}$ $(1 \mathrm{~mL})$ recovering the magnetic particles. The collected supernatants had their absorbancies at $280 \mathrm{~nm}$ and HA analyzed; PAGE for native and basic proteins were performed according to Reisfeld et al. [14].

\section{Results and Discussion}

C. mollis (Camaratu bean) is a native forage from the Semi-Arid Region of Pernambuco State, Northeastern of Brazil, and belongs to Fabaceae family, taxonomically related with $C$. ensiformis species from which seeds are obtained Con A. C. mollis seeds have been considered an important lectin source, giving multiple Cramoll molecular forms with different carbohydrate specificities: Cramoll 1, Cramoll 2, and Cramoll 4 are specific for glucose/mannose whereas Cramoll 3 is galactose specific. A preparation containing Cramoll 1 and Cramoll 4 together (Cramoll 1,4) showed a higher hemagglutinating activity (HA) when compared with the isolated Cramoll 1 and Cramoll 4 as well as Con A. These lectin preparations (Cramoll 1, Cramoll 4, and Cramoll $1,4)$ are inhibited by different carbohydrates (D-glucose, Dmannose, $\alpha$-D-methyl-mannoside, and $\mathrm{D}$-fructose, among others) in distinct concentrations. Cramoll 1,4 and Cramoll 


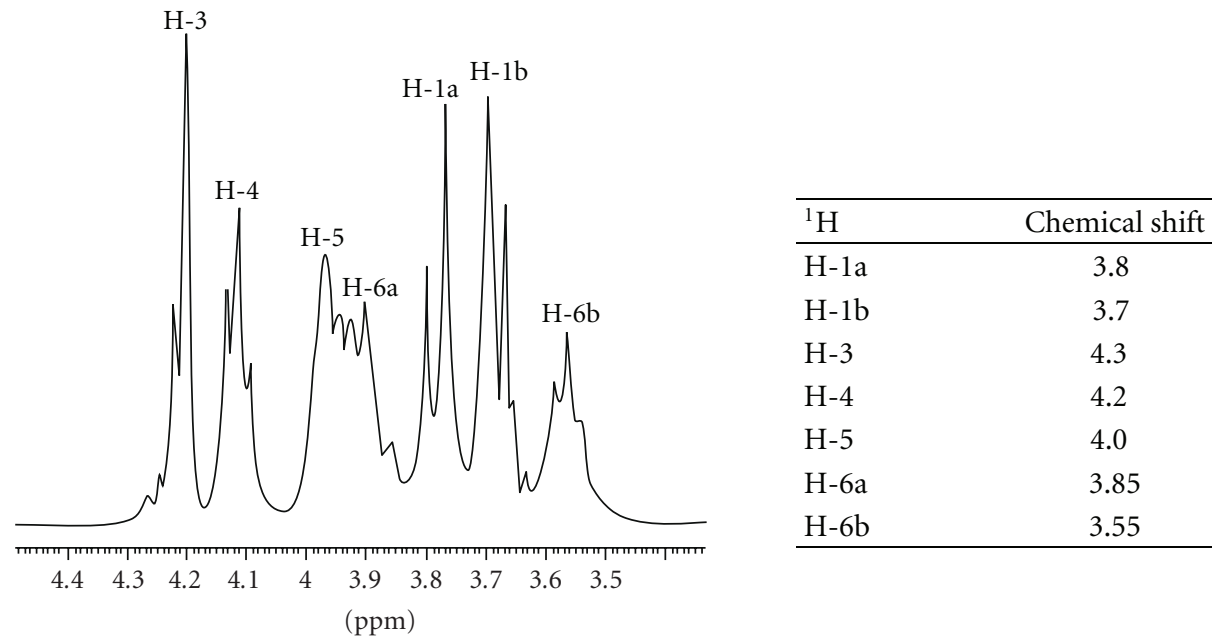

Figure 1: ${ }^{1} \mathrm{H}$ NMR spectra of levan from Zymomonas mobillis (ZAG-12L). The spectrum was recorded at $60^{\circ} \mathrm{C}$ for sample in $\mathrm{D}_{2} \mathrm{O}$ solution. The table shows the chemical shift.

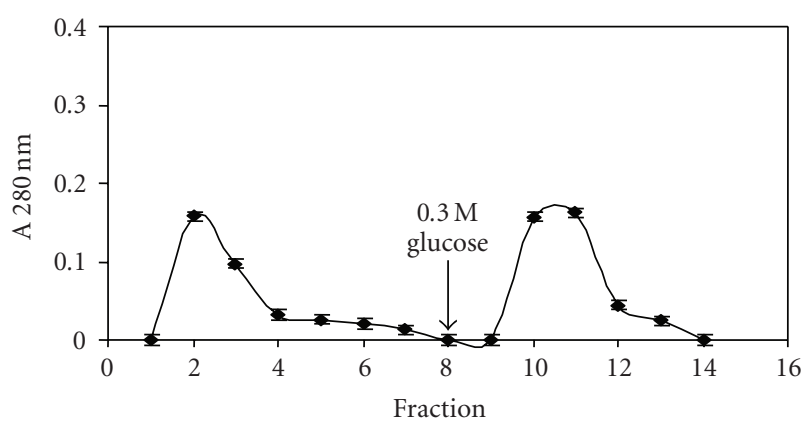

Figure 2: Affinity binding of Con A on FMZAG-12L. An amount of $1.5 \mathrm{mg}$ of Con A was incubated with the magnetic particles and firstly eluted with buffer and glucose afterwards (arrow). Fractions $(1 \mathrm{~mL})$ were collected and their absorbance at $280 \mathrm{~nm}$ established. Each bar represents the mean \pm SD of four experiments using the same FMZAG-12L particles.

1 were successfully used in different biological assays as well as in structural and electrochemical studies [15-21].

The NMR analysis of ZAG-12L used in this work revealed a spectrum profile corresponding to the fructose residues protons. ${ }^{1} \mathrm{H}$ NMR spectrum shows seven protons between 3.4 and $4.2 \mathrm{ppm}$ indicating that the polysaccharide produced by $Z$. mobilis was levan type with the linkage of $(2 \rightarrow 6)$ fructofuranoside (Figure 1). No signals in the anomeric region (5.3 to $4.3 \mathrm{ppm}$ ) were found, confirming the absence of anomeric protons. The simplicity of the spectrum reflects that this polysaccharide is a homopolymer of fructose. Levans from Erwinia herbicola [22], Acetobacter xylinum [23], and Bacillus subtilis (Natto) [24] showed the same structural characteristics analyzed by NMR.

HAI of Cramoll 1, Cramoll 1,4, Cramoll 3, and Con A by fructose and levan revealed that all lectins presented HA inhibited by fructose and its polymeric derivative (Table 1). However, inhibition of Cramoll 1, 4 activity by the commercially acquired levan was less intensive. Previous studies of
TABLE 1: Hemagglutinating activity inhibition of Cramoll 1, Cramoll 1, 4, Cramoll 3, and Con A by fructose and levans.

\begin{tabular}{lcccc}
\hline & \multicolumn{4}{c}{ Reciprocal titers (HA) } \\
$\begin{array}{l}\text { Carbohydrate } \\
(200 \mathrm{mM})\end{array}$ & Cramoll 1,4 & Cramoll 1 & Cramoll 3 & Con A \\
\hline Absence & 4096 & 256 & 512 & 2048 \\
Fructose & 2 & 2 & 2 & 4 \\
ZAG-12L & 32 & 2 & 0 & 2 \\
Levan (Sigma) & 1024 & 8 & 8 & 8 \\
\hline
\end{tabular}

The activity was made with $2.5 \%(\mathrm{v} / \mathrm{v})$ suspension of glutaraldehyde treated rabbit erythrocytes.

this preparation specificity using different monosaccharides showed that D-fructose inhibited Cramoll 1,4 HA at the same D-mannose proportion [10]. Mo et al. [25] reported that Con A did bind to D-fructofuranosyl groups present in plant and microorganism levans whereas banana (Musa acuminate) lectin reacted only with microorganism levans. It is important to observe that banana lectin and Con A (structurally similar to Cramoll 1) are both glucose/mannose specific.

The inhibition of lectins by levans suggested that magnetized levan could be potentially used as an affinity matrix to investigate or purify lectins that recognize fructose. Figure 2 shows the Con A elution profile by using particles of ferromagnetic levan composite (FMZAG-12L). Proteins unspecifically bound to the particles were completely washed out with $0.15 \mathrm{M} \mathrm{NaCl}$ from the 1 st to the 8 th washes $(8 \mathrm{~mL})$ and a second peak emerged after $0.3 \mathrm{M}$ glucose addition at the 10-11th fractions. It is worthwhile to draw attention to the fact that equal profile was attained four times indicating its reproducibility and the reuse of the particles. Figure $3(\mathrm{a})$ represents Cramoll 1, 4 capacity to complex to FMZAG-12L. This preparation containing both lectin isoforms was previously purified from $C$. mollis seed extract by ammonium sulfate fractionation and affinity chromatography in Sephadex 


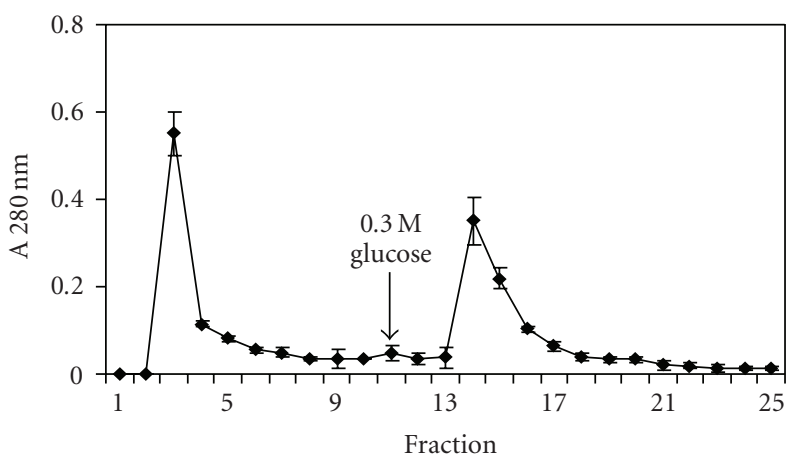

(a)

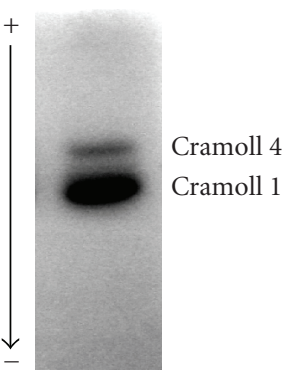

(b)

Figure 3: Affinity binding of Cramoll 1,4 on FMZAG-12L. An amount of $1.5 \mathrm{mg}$ of Cramoll 1, 4 was incubated with the magnetic particles and eluted with buffer and glucose afterwards (arrow). (a) Fractions ( $1 \mathrm{~mL}$ ) were collected and their absorbance at $280 \mathrm{~nm}$ established (a). Each bar represents the mean \pm SD of four experiments using the same FMZAG-12L particles. (b) Electrophoresis to native and basic protein $(100 \mu \mathrm{g})$ from the 14 th and 15 th fractions, stained with Amido Black.

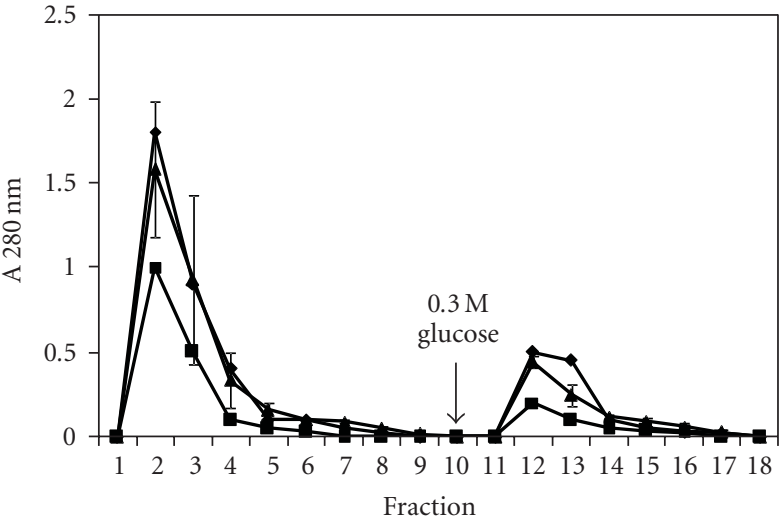

(a)

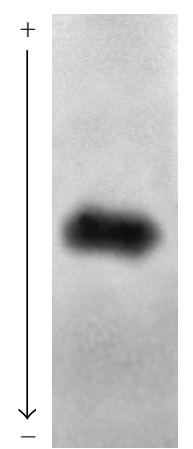

(b)

Figure 4: Affinity binding of F40-60 on FMZAG-12L. Aliquots of $18 \mathrm{mg}(\boldsymbol{\square}), 10 \mathrm{mg}(\bullet)$ and $5 \mathrm{mg}(\circ)$ were incubated with the magnetic particles and eluted with buffer and glucose (arrow). (a) Fractions $(1 \mathrm{~mL}$ ) were collected and their absorbance at $280 \mathrm{~nm}$ measured (a). Each bar represents the mean \pm SD of four experiments using the same FMZAG-12L particles when $10 \mathrm{mg}$ of F40-60 were used. (b) Electrophoresis to native and basic protein $(100 \mu \mathrm{g})$ from the $10 \mathrm{mg}$ protein F40-60 profile of the 10th and 11th fractions was stained with Amido Black.

G-75 [10]. The particles washed with $0.15 \mathrm{M} \mathrm{NaCl}$ again showed that from the 1 st to 8 th fraction ( $8 \mathrm{~mL}$ of washes) all unspecifically bound proteins were removed and a second peak emerged after $0.3 \mathrm{M}$ glucose introduction. Similar to Con A purification this procedure was four times reproduced using the same FMZAG-12L. The protein peak eluted at the 14th fraction showed two bands (Cramoll 1 and Cramoll 4) by polyacrylamide electrophoresis to basic and native proteins (Figure 3(b)) similar to previously reported pattern [10]. None specific binding to FMZAG-12L was detected when Cramoll 3 was used (data not shown). Recently, the importance of protein-protein interaction has been pointed out in certain oligomeric lectins since differences among their quaternary organizations appear to be directly related to those among their functions [26]. Lectin binding sites have been deeply characterized by many workers to understand carbohydrate interaction of these versatile proteins [27-29].
The evaluation of FMZAG-12L to purify Cramoll lectins from F40-60 preparation is presented in Figure 4(a). Three different concentrations of the ammonium sulfate preparation per $10 \mathrm{mg}$ of FMZAG-12L were used: $1.8 \mathrm{mg} / \mathrm{mg}$, $1 \mathrm{mg} / \mathrm{mg}$, and $0.5 \mathrm{mg} / \mathrm{mg}$ of protein/mg magnetic particles. All concentrations showed a second protein peak (9th-10th fractions) eluted by $0.3 \mathrm{M}$ glucose addition at the 8 th washing with $0.15 \mathrm{M} \mathrm{NaCl}$. The polyacrylamide gel electrophoresis to basic and native proteins of the fraction (10th) collected from the $10 \mathrm{mg}$ F40-60 purification showed only Cramoll 1 protein band (Figure 4(b)). Furthermore, the pure lectin Cramoll 1 showed HA of 256 and was inhibited by all levans (Table 1). The purification of this lectin is relevant due to its several applications such as neoplastic tissue marker. Cramoll 1 showed a higher intensity of staining to transformed tissues than normal ones [30]: also, encapsulation of Cramoll 1 into liposomes produced an improvement in its in vivo 
antitumor activity against Sarcoma 180 compared with free Cramoll 1 solution [19]. The lectin purification using only the ferromagnetic particles, namely, absent of levan, did not show any protein peak after $0.3 \mathrm{M}$ glucose addition (control). It is interesting to notice that Cramoll 4 was collected when a purified preparation was incubated with the FMZAG-12L (Figure 3(b)) but it was not obtained when a lesser purified preparation (F40-60) was used (Figure 4(b)). Probably, higher amounts of Cramoll 1 than Cramoll 4 in preparation F40-60 and/or different binding constant values for the magnetic levan-lectin can justify these discrepancies.

Furthermore, the ferromagnetic composite of levan is synthesized by a simple and inexpensive method. Cramoll 1 was purified by this fast two-step procedure (ammonium sulfate fractionation and FMZAG-12L affinity binding) instead of the laborious and time consuming three-step protocol previously described [10]. Finally, it is important to investigate if other polysaccharides could replace the levan in the composite synthesis and be used to lectin purification.

\section{Acknowledgments}

This paper was financially supported by the Conselho Nacional de Desenvolvimento Científico e Tecnológico (CNPq). The authors are deeply grateful to the technical assistance of Mrs. Maria Barbosa Reis da Silva and Mr. João Virgínio da Silva.

\section{References}

[1] K. Larsen, M. B. Thygesen, F. Guillaumie, W. G. T. Willats, and K. J. Jensen, "Solid-phase chemical tools for glycobiology," Carbohydrate Research, vol. 341, no. 10, pp. 1209-1234, 2006.

[2] I. Safarik and M. Safarikova, "Magnetic techniques for the isolation and purification of proteins and peptides," BioMagnetic Research and Technology, vol. 2, article 7, pp. 1-17, 2004.

[3] A. M. A. Carneiro Leão, E. A. Oliveira, and L. B. Carvalho Jr., "Immobilization of protein on ferromagnetic Dacron," Applied Biochemistry and Biotechnology, vol. 31, no. 1, pp. 53$58,1991$.

[4] S. M. B. Pinheiro, L. B. Carvalho Jr., and M. E. C. Chaves, "The use of ferromagnetic Dacron as solid-phase in chemiluminescent assays," Biotechnology Techniques, vol. 13, no. 12, pp. 919922, 1999.

[5] R. A. L. Coêlho, G. A. Jaques, A. D. Barbosa, et al., "Magnetic polysiloxane-polyvinyl alcohol composite as solid-phase in chemiluminescent assays," Biotechnology Letters, vol. 24, no. 20, pp. 1705-1708, 2002.

[6] I. P. G. Amaral, M. G. Carneiro-da-Cunha, L. B. Carvalho Jr., and R. S. Bezerra, "Fish trypsin immobilized on ferromagnetic Dacron," Process Biochemistry, vol. 41, no. 5, pp. 1213-1216, 2006.

[7] S. G. De-Simone, C. C. Netto, and F. P. Silva Jr., "Simple affinity chromatographic procedure to purify $\beta$-galactoside binding lectins," Journal of Chromatography B, vol. 838, no. 2 , pp. 135-138, 2006.

[8] P. Gemeiner, D. Mislovičová, J. Tkáč, et al., "Lectinomics: II. A highway to biomedical/clinical diagnostics," Biotechnology Advances, vol. 27, no. 1, pp. 1-15, 2009.

[9] P. M. G. Paiva and L. C. B. B. Coelho, "Purification and partial characterization of two lectins isoforms from Cratylia mollis mart. (Camaratu bean)," Applied Biochemistry and Biotechnology, vol. 36, no. 2, pp. 113-118, 1992.

[10] M. T. S. Correia and L. C. B. B. Coelho, "Purification of a glucose/mannose specific, isoform 1, from seeds of Cratylia mollis Mart. (Camaratu bean)," Applied Biochemistry and Biotechnology, vol. 55, no. 3, pp. 261-273, 1995.

[11] A. Heebøll-Nielsen, M. Dalkiær, J. J. Hubbuch, and O. R. T. Thomas, "Superparamagnetic adsorbents for highgradient magnetic fishing of lectins out of legume extracts," Biotechnology and Bioengineering, vol. 87, no. 3, pp. 311-323, 2004.

[12] M. Šafaříková and I. Šafařík, "One-step partial purification of Solanum tuberosum tuber lectin using magnetic chitosan particles," Biotechnology Letters, vol. 22, no. 11, pp. 941-945, 2000.

[13] O. H. Lowry, N. J. Rosebrough, A. L. Farr, and R. J. Randall, "Protein measurement with the folin phenol reagent," The Journal of Biological Chemistry, vol. 193, no. 1, pp. 265-275, 1951.

[14] R. A. Reisfeld, U. J. Lewis, and D. E. Williams, "Disk electrophoresis of basic proteins and peptides on polyacrylamide gels," Nature, vol. 195, no. 4838, pp. 281-283, 1962.

[15] A. Baszkin, M.-M. Boissonnade, N. S. Santos-Magalhaes, L. B. Carvalho Jr., M. T. S. Correia, and L. C. B. B. Coelho, "Cratylia mollis lectin at the air-aqueous solution interface: adsorption and lectin-lipid interactions," Colloids and Surfaces B, vol. 17, no. 3, pp. 191-201, 2000.

[16] S. R. Souza, M. T. S. Correia, M. M. A. Pessoa, J. F. Kennedy, J. L. Lima-Filho, and L. C. B. B. Coelho, "A novel model to characterize the electric double layer of lectins from Cratylia mollis (Camaratu bean) and Canavalia ensiformis adsorbed on metallic surface," Carbohydrate Polymers, vol. 46, no. 2, pp. 191-193, 2001.

[17] C. O. Nascimento, L. C. B. B. Coelho, M. T. S. Correia, and M. G. Carneiro-da-Cunha, "Liquid-liquid extraction of lectin from Cratylia mollis seeds using reversed micelles," Biotechnology Letters, vol. 24, no. 11, pp. 905-907, 2002.

[18] S. R. Souza, R. F. Dutra, M. T. S. Correia, M. M. A. Pessoa, J. L. Lima-Filho, and L. C. B. B. Coelho, "Electrochemical potential of free and immobilized Cratylia mollis seed lectin," Bioresource Technology, vol. 88, no. 3, pp. 255-258, 2003.

[19] C. A. S. Andrade, M. T. S. Correia, L. C. B. B. Coelho, S. C. Nascimento, and N. S. Santos-Magalhães, "Antitumor activity of Cratylia mollis lectin encapsulated into liposomes," International Journal of Pharmaceutics, vol. 278, no. 2, pp. 435445, 2004.

[20] E. V. M. Maciel, V. S. Araújo-Filho, M. Nakazawa, Y. M. Gomes, L. C. B. B. Coelho, and M. T. S. Correia, "Mitogenic activity of Cratylia mollis lectin on human lymphocytes," Biologicals, vol. 32, no. 1, pp. 57-60, 2004.

[21] A. C. O. Santos, C. A. Peixoto, and L. C. B. B. Coelho, "Ultrastructural analysis and immunocytochemical localization of isolectins in Cratylia mollis seeds," Micron, vol. 35, no. 7, pp. 613-618, 2004.

[22] J. D. Blake, M. L. Clarke, P. E. Jansson, and K. E. McNeil, "Fructan from Erwinia herbicola," Journal of Bacteriology, vol. 151, no. 3, pp. 1595-1597, 1982.

[23] K. Tajima, N. Uenishi, M. Fujiwara, T. Erata, M. Munekata, and M. Takai, "The production of a new water-soluble polysaccharide by Acetobacter xylinum NCI 1005 and its structural analysis by NMR spectroscopy," Carbohydrate Research, vol. 305, no. 1, pp. 117-122, 1997.

[24] I. L. Shih, Y. T. Yu, C. J. Shieh, and C.-Y. Hsieh, "Selective production and characterization of levan by Bacillus subtilis 
(Natto) Takahashi," Journal of Agricultural and Food Chemistry, vol. 53, no. 21, pp. 8211-8215, 2005.

[25] H. Mo, H. C. Winter, E. J. M. Van Damme, W. J. Peumans, A. Misaki, and I. J. Goldstein, "Carbohydrate binding properties of banana (Musa acuminata) lectin. I. Novel recognition of internal $\alpha 1,3$-linked glucosyl residues," European Journal of Biochemistry, vol. 268, no. 9, pp. 2609-2615, 2001.

[26] I. Vīna, A. Karsakevich, and M. Bekers, "Stabilization of anti-leukemic enzyme L-asparaginase by immobilization on polysaccharide levan," Journal of Molecular Catalysis B, vol. 11, no. 4-6, pp. 551-558, 2001

[27] I. Roy, M. Sardar, and M. N. Gupta, "Cross-linked alginateguar gum beads as fluidized bed affinity media for purification of jacalin," Biochemical Engineering Journal, vol. 23, no. 3, pp. 193-198, 2005.

[28] K. Yamamoto, S. Ito, F. Yasukawa, Y. Konami, and N. Matsumoto, "Measurement of the carbohydrate-binding specificity of lectins by a multiplexed bead-based flow cytometric assay," Analytical Biochemistry, vol. 336, no. 1, pp. 28-38, 2005.

[29] S. Banerjee, S. Chaki, J. Bhowal, and B. P. Chatterjee, "Mucin binding mitogenic lectin from freshwater Indian gastropod Belamyia bengalensis: purification and molecular characterization," Archives of Biochemistry and Biophysics, vol. 421, no. 1, pp. 125-134, 2004.

[30] E. I. C. Beltrão, M. T. S. Correia, J. Figueredo-Silva, and L. C. B. B. Coelho, "Binding evaluation of isoform 1 from Cratylia mollis lectin to human mammary tissues," Applied Biochemistry and Biotechnology, vol. 74, no. 3, pp. 125-134, 1998. 

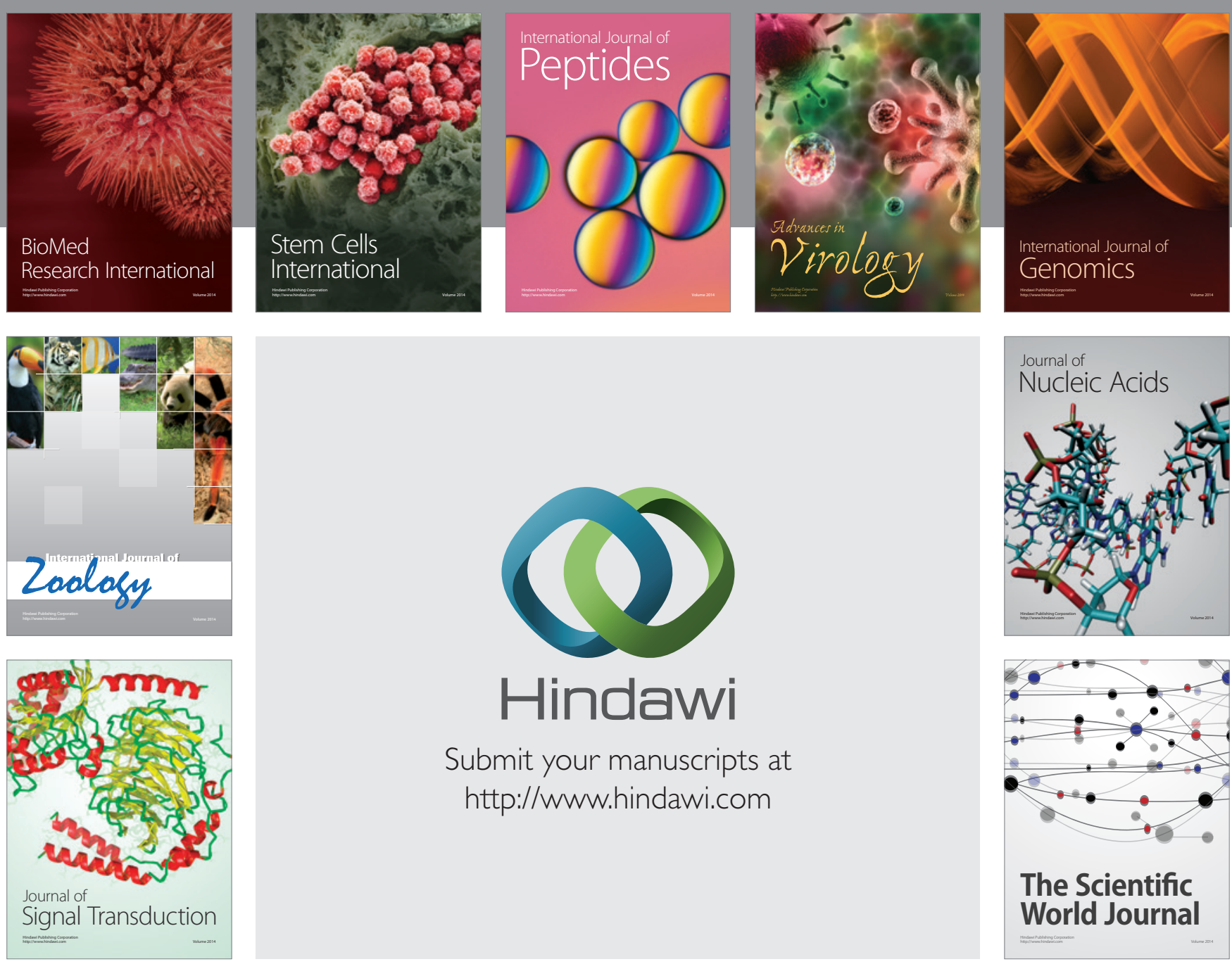

Submit your manuscripts at

http://www.hindawi.com
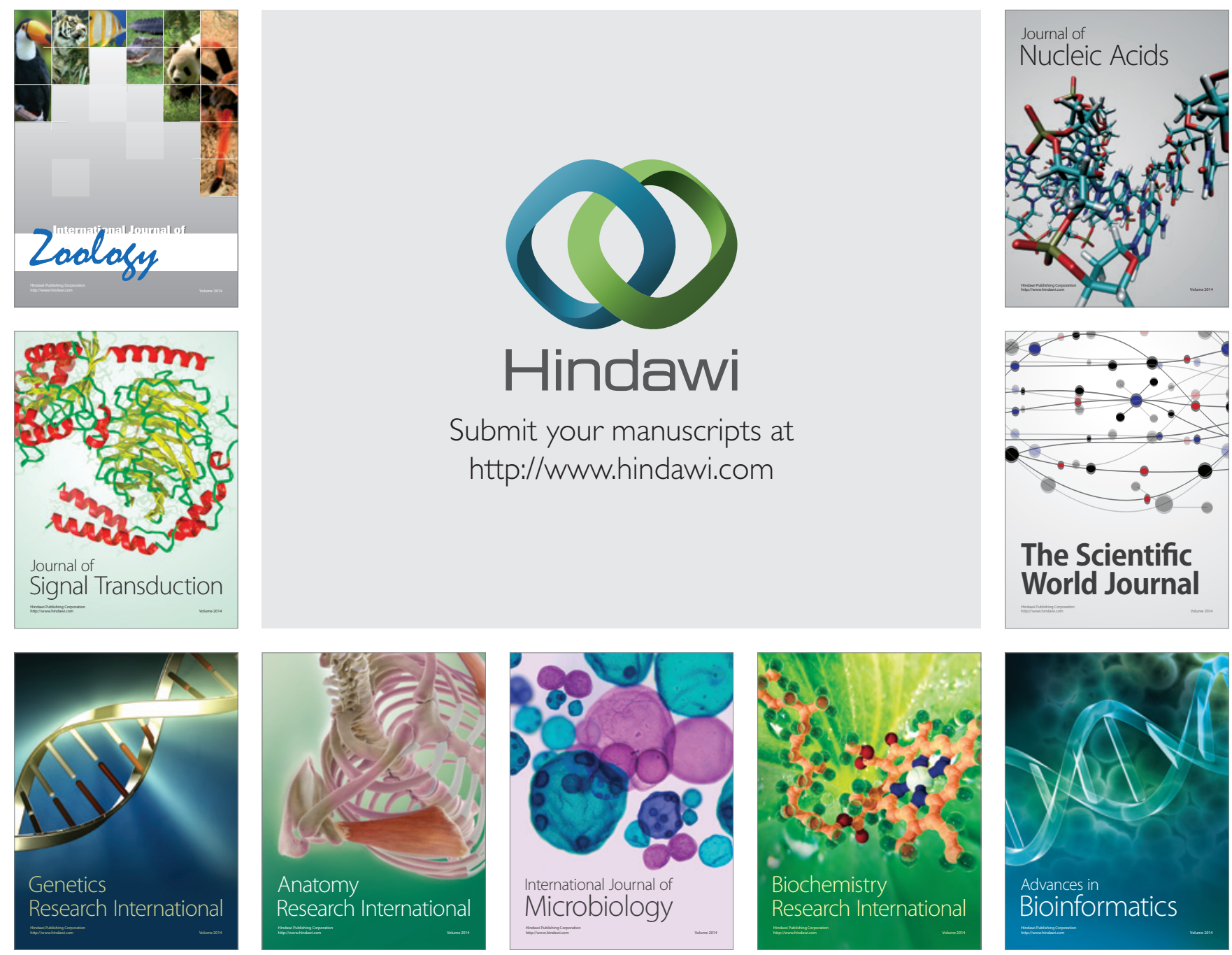

The Scientific World Journal
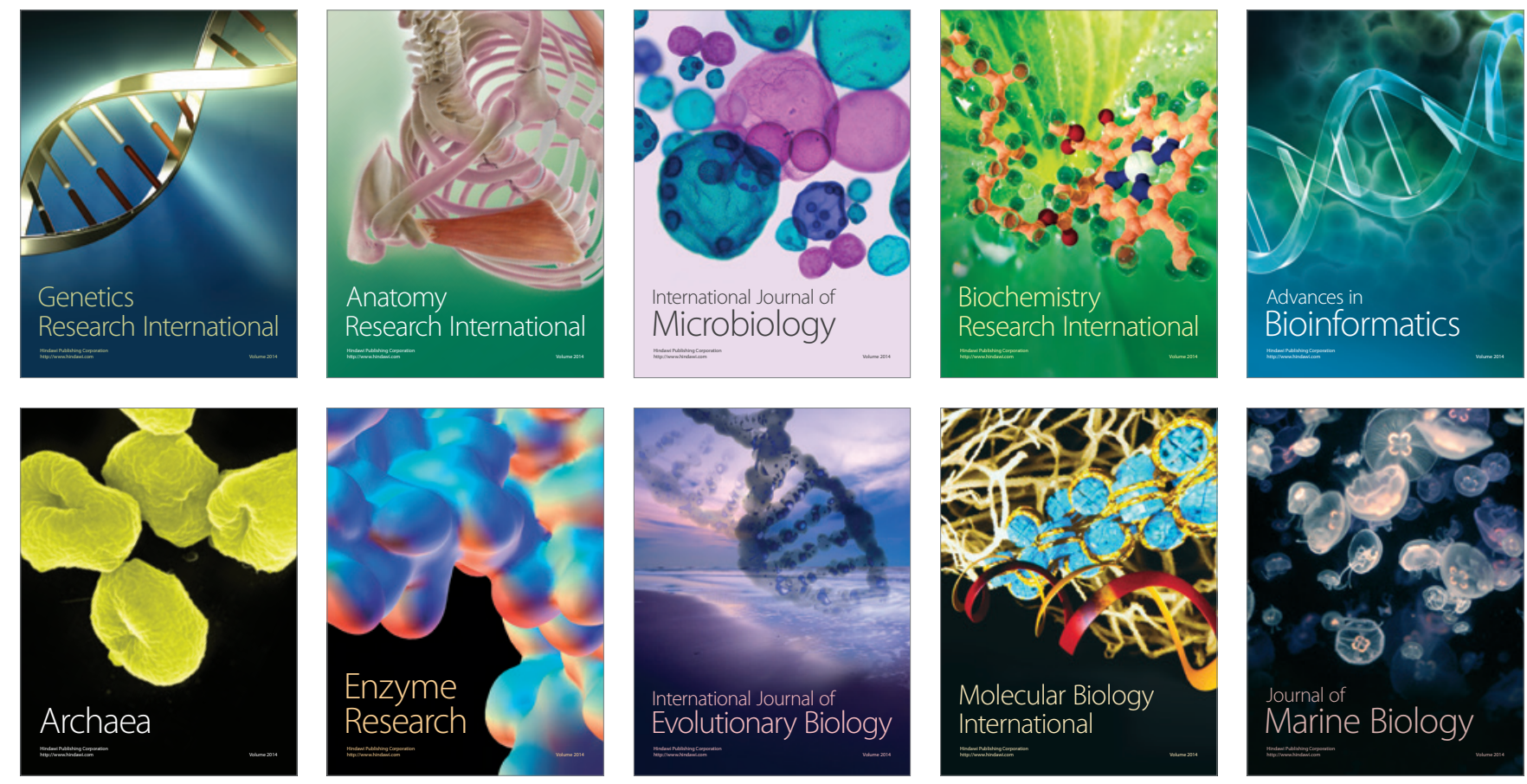